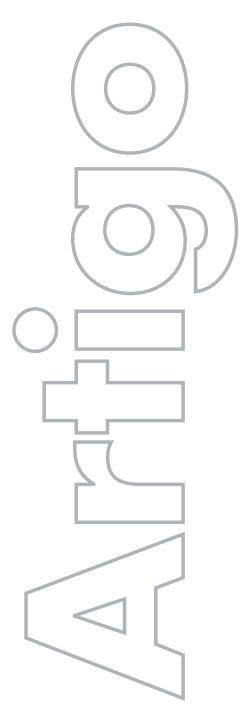

revista

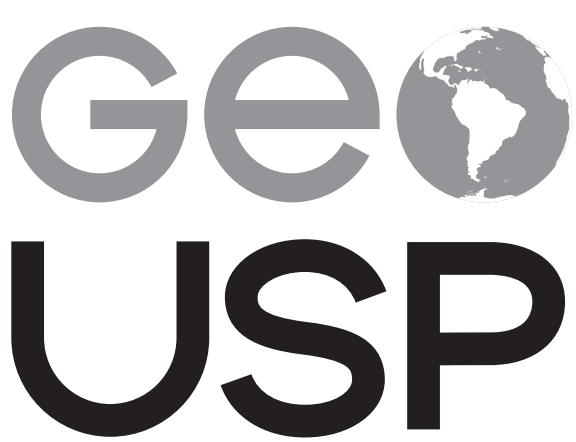

espaço e tempo

Volume $23 \cdot n^{\circ} 1$ (2019)

ISSN 2179-0892
Formação socioespacial e cidades pequenas: um segmento da rede urbana na porção meridional de Mato Grosso do Sul

\author{
Paulo Fernando Jurado da Silva \\ UEMS \\ e-mail: pfjurado@uol.com.br
}

Mara Lucia Falconi da Hora Bernardelli

UEMS

e-mail: marahora@uems.br

p. $163-181$

Como citar este artigo:

SILVA, P. F. J.; BERNARDELLI, M. L. F. H. Formação socioespacial e cidades pequenas: um segmento da rede urbana na porção meridional de Mato Grosso do Sul. Geousp Espaço e Tempo (Online), v. 23, n. 1, p. 163-181, abr. 2019. ISSN 2179-0892.

Disponível em: https://www.revistas.usp.br/geousp/article/ view/137104. doi: https://doi.org/10.11606/issn.2179-0892. geousp.2019.137104.

\section{(c) $(1) \circledast$}

Este artigo está licenciado sob a Creative Commons Attribution 4.0 License. 


\title{
Formação socioespacial e cidades pequenas: um segmento da rede urbana na porção meridional de Mato Grosso do Sul
}

\section{Resumo}

Apesar de compor a maior fatia do total de cidades do quadro urbano brasileiro, as cidades pequenas tinham pouco destaque nas pesquisas acadêmicas, $O$ que vem mudando em função do crescente interesse pelo tema. Em Mato Grosso do Sul, essa realidade não é diferente, apresentando o estado um número inexpressivo de municípios frente a outros pontos do país e mesmo com sua imensa extensão territorial. Diante disso, o objetivo aqui é analisar um segmento específico dessa rede, focalizando a microrregião de Iguatemi, predominantemente constituída por cidades pequenas. Baseamo-nos na leitura e na avaliação de material bibliográfico, bem como na coleta e na sistematização de dados e informações de fontes secundárias. Os resultados alcançados permitem discutir a complexidade que envolve essa microrregião, sublinhando aspectos históricos e geográficos da formação socioespacial da área em tela.

Palavras-chave: Cidades pequenas. Rede urbana. Formação socioespacial. Microrregião de Iguatemi. Mato Grosso do Sul.

\section{Socio-spatial formation and small cities: a segment of the urban network in the southern portion of Mato Grosso do Sul}

\begin{abstract}
Small cities, although they make up the largest share of cities in the Brazilian urban context, have been less prominent in academic researches, which is not currently observed, because there is a growing interest in the subject. In Mato Grosso do Sul, this reality is also no different, showing the state an unimpressive number of municipalities when compared to other realities of the
\end{abstract}


country, despite its immense territorial extension. In view of the above, the objective of this article is to analyze a specific segment of this network, focusing on the Iguatemi Microregion, which consists predominantly of small towns. We are based on the reading and evaluation of bibliographic materials about it, as well as on the collection and systematization of data and secondary source information for the construction of this text. The results achieved allow us to discuss the complexity that surrounds the microregion, emphasizing historical and geographical aspects about the socio-spatial formation of the area selected for this study.

Keywords: Small cities. Urban network. Socio-spatial formation. Microregion of Iguatemi. Mato Grosso do Sul.

\section{Introdução}

Na Geografia, o tema das cidades pequenas tem ganhado importância nos últimos anos, apesar de não ser um dos principais: "os esforços de reflexão empreendidos sobre o espaço urbano e a cidade têm preferencialmente privilegiado as grandes cidades" (Corrêa, 1999, p. 45). Por reunir mais condições econômicas, sociais e políticas, as de maior porte acabam sendo mais estudadas que as pequenas. Entretanto, há de se ressaltar que essas últimas conformam um número bastante expressivo de cidades, tanto no Brasil quanto no quadro urbano mundial, o que requer, por sua vez, a atenção e a análise por parte da comunidade científica.

No caso brasileiro, estudos de autores como Roberto Lobato Corrêa e Milton Santos têm sido largamente utilizados por vários trabalhos para debater o tema, embora Santos (1979) tenha usado expressões como cidades locais e pseudocidades para falar do tema.

Com o passar do tempo, outros estudos foram surgindo, a exemplo dos que versam sobre a reprodução social e a produção de moradias (Bernardelli, 2004), papéis e significados urbanos (Endlich, 2006), discussão do plano diretor (Soares, 2008), a rede urbana no oeste paulista (Fresca, 1990) e o debate conceitual das cidades pequenas (Jurado da Silva; Sposito, 2009), entre outros.

Trata-se, assim, de um tema pertinente, uma vez que estamos diante de uma urbanização que apresenta forte heterogeneidade e complexidade. $\bigcirc$ Brasil tem mais de 5.570 municípios, grande parte dos quais tem como sede administrativa pequenos centros urbanos, revelando uma realidade multifacetada (IBGE, 2017a).

Isso se revela também na realidade de Mato Grosso do Sul, que tem 79 municípios, sendo a maioria conformada por cidades de pequeno porte. A rede urbana sul-mato-grossense é territorialmente ampla, embora o estado seja pouco populoso e apresente um quociente demográfico concentrado na capital e em algumas poucas cidades como Dourados, Corumbá e Três Lagoas. 
Em Mato Grosso do Sul, apenas quatro municípios têm população superior a 100 mil habitantes: ' Campo Grande (863.982), Dourados (215.486), Três Lagoas (115.561) e Corumbá (109.294), perfazendo 1.304.323 habitantes, ou 48,62\% do total. Entre 40 mil e 90 mil habitantes, há sete localidades, concentrando as demais (68) 51,38\% da população total.

Importa destacar que, segundo o Censo Demográfico de 2010 (IBGE, 2010), 14,35\% do total da população sul-mato-grossense vivem no campo, havendo municípios como Japorã, onde apenas 18\% de 7.731 habitantes vivem na área urbana; Jaraguari, por sua vez, com 6.341 habitantes, tem 28\% de população urbana: são no total 13 municípios com população rural igual ou inferior a 50\% e população total inferior a 20 mil habitantes (IBGE, 2010). Esse aspecto peculiar do estado deve-se ao processo histórico de sua ocupação, sendo que só no contexto do Estado Novo, sob o comando de Getúlio Vargas, com o projeto denominado "Marcha para o Oeste", a porção sul do então estado de Mato Grosso passa a ser mais efetivamente povoada por população não indígena (Oliveira, 2013).

Nesse cenário, vale ressaltar que há diferentes formas de compreender as cidades pequenas, entre as quais destacamos duas. A primeira concebe esse conjunto de cidades, com papéis urbanos bastante restritos, como decorrente da lógica contraditória própria da expansão do capitalismo. Nessa vertente, considera-se que a difusão da urbanização promove profundas mudanças nas relações, instaurando o domínio da propriedade privada e expressando-se em muitos conflitos e contradições. Baseada na concepção teórica de Lefebvre, essa análise aparece, por exemplo, em Carlos:

Nesta direção o urbano e o rural aparecem num movimento da reprodução saído da história da industrialização. Não se pode ignorar que a industrialização permitiu o desenvolvimento do mundo da mercadoria; nesta direção a generalização do valor de troca invadiu a vida cotidiana capturando o tempo cíclico da vida e submetendo-o ao tempo linear da indústria; articulou as mais distantes áreas do planeta, desenvolvendo a rede de comunicação e difundindo a informação, com a evidente hierarquização dos lugares no espaço entre dominantes e dominados. No espaço permitiu a realização da propriedade privada da terra, ao longo do processo histórico, pela generalização da mercadoria espaço. Criou um processo inexorável: a urbanização do planeta; mas o problema que se coloca não é o número de cidades que o IBGE contabiliza, do número de pessoas que vive num ou noutro lugar, mas o modo como esta sociedade (urbana) como horizonte, pode ser entendida [...] (Carlos, 2007, p. 107).

Nessa perspectiva, o surgimento da indústria e o processo de industrialização promoveram transformações econômicas, estendendo o domínio capitalista no território, situação em que o universo urbano "explode", tanto na perspectiva de sua extensão material quanto simbólica, relativa ao modo de vida: 'A construção do 'urbano' supõe a superação dessa divisão, a

1 Estimativa populacional do IBGE referente ao ano de 2016. 
sociedade urbana se estende planetariamente, mas sem supor o desaparecimento das atividades agrícolas; cidade e campo permanecem, as relações se transformam e as formas ganham novos conteúdos" (Sobarzo, 2006, p. 61).

A segunda perspectiva para entender as cidades pequenas é a análise do espaço por meio da interpretação de seus conteúdos. Em outras palavras, tratamos da interpretação de dois conceitos caros à Geografia e às Ciências Humanas: rural e urbano, ambos vistos no plano de suas relações. Nesse sentido, admite-se que não houve uma homogeneização de conteúdos e das formas espaciais historicamente pensadas e concebidas para a compreensão da sociedade e dos diferentes modos de vida que compõem o mosaico cultural, sociológico e antropológico da realidade. Por isso, não há o "fim do rural", mas uma nova interpretação das atividades econômicas que o constituem a partir da tecnificação e da industrialização.

A partir dessa compreensão, observa-se que características próprias do modo de vida urbano podem estar também no espaço rural e vice-versa, como conteúdo e como objeto atrelados ao domínio da lógica econômica hegemônica. Com isso, avalia-se que a expressão da ruralidade pode-se apresentar na cidade ou naquilo que é legalmente considerado como tal, podendo-se mencionar então um espaço urbano formado por pessoas que trabalham e se reproduzem socialmente como se estivessem no campo. Isso resulta especialmente do processo de expansão do capitalismo, que se baseia na exploração e na expropriação do trabalhador pela apropriação de áreas destinadas especificamente à produção de commodities.

Nesse sentido, é preciso deixar claro que essas perspectivas teóricas podem servir para compreender analítica e conceitualmente trabalhos científicos na área de Geografia e ciências afins. No caso da abordagem do texto, é importante destacar que o rural se expressa intensamente em seu conteúdo e, portanto, algumas inquietações surgiram no momento da redação, a exemplo de como o espaço rural se apresenta a partir da dinâmica capitalista na formação socioespacial da microrregião de Iguatemi: é a manifestação do extravasamento urbano das ordens de comando em direção ao campo ou apenas um reforço do conteúdo rural na sua essência, articulado às lógicas maiores de produção? No texto, ficará evidente que essas lógicas estão relacionadas à dinâmica de comando citadina, embora o processo seja permeado por contradições e sejam observadas, nessa trama, características de ruralidades nas cidades, porque a dimensão da produção do campo é muito importante no produto interno bruto dos diferentes municípios que a compõem, bem como no modo de vida da população.

Assim, tomando essas noções preliminares como balizas, o objetivo deste artigo é analisar um segmento específico da rede urbana em Mato Grosso do Sul focalizando a microrregião de Iguatemi (Figura 1), ${ }^{2}$ constituída predominantemente por centros locais, debatendo, para tanto, temas como cidades pequenas, formação socioespacial e rede urbana.

\footnotetext{
2 A Figura 1 tem como base o estudo da Região de Influência das Cidades (Regic) produzido pelo IBGE (2008), com pequenas adaptações para dar maior clareza ao mapa. Assim, usamos a expressão capital regional sem as letras (A, B, C) que a acompanham no estudo da Regic e optamos por discriminar apenas maior ou menor hierarquia no nível.
} 
Figura 1 - Localização da microrregião de Iguatemi-MS

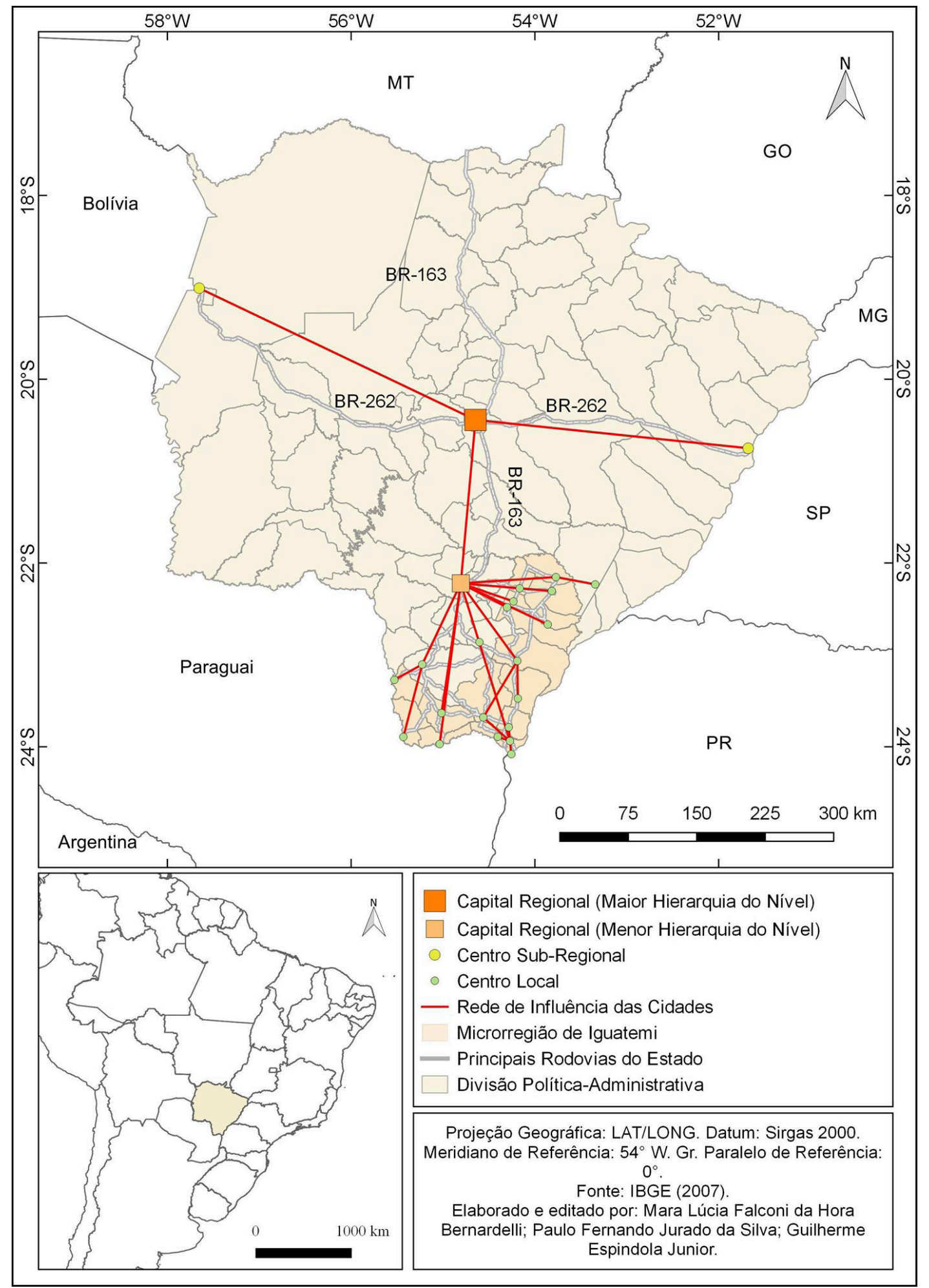

Tendo em vista a gênese de vários dos municípios do recorte espacial, observou-se que a influência da maior cidade da porção meridional do estado é de Dourados, reiterando a importância da formação socioespacial, cujo sentido inicial estava ligado à Colônia Agrícola Nacional de Dourados (Cand). As interações socioespaciais que até hoje estão presentes têm, portanto, ligação com a herança passada deste processo. Além disso, ressalta-se que a conexão entre esses centros é mais unidirecional, visto que é Dourados que recebe os fluxos das cidades vi- 
zinhas, e não o contrário. Assim, frisa-se a capilaridade deste centro regional (capital regional), no que tange aos fluxos, especialmente, de serviços e comerciais que acaba permeando na atração de pessoas e mercadorias, no âmbito da influência regional. Em outras palavras, as cidades que compõem a referida microrregião são pouco expressivas por sua influência espacial, ou seja, têm um alcance espacial mínimo, que se circunscreve essencialmente em seu território municipal, com poucas exceções, como Ivinhema e Naviraí, que abrigam empresas relevantes na compreensão do cenário econômico e na identificação de nexos globais que extrapolam a localidade, como será destacado adiante.

Para tanto, discutimos a rede urbana e a formação socioespacial enfatizando que, dadas a grande extensão do território brasileiro e as enormes diferenças nele presentes, há uma vasta gama de segmentos da rede urbana com características muito singulares, o que nos permite tratá-las a partir do conceito de formação socioespacial. Em seguida, enfatizamos aspectos da microrregião de Iguatemi e sua inserção na rede urbana, identificando os principais papéis urbanos desse espaço.

\section{A rede urbana: um debate necessário para a leitura da urbanização}

Os estudos sobre as redes urbanas têm início na década de 1920. Não é uma coincidência; no começo do século XX, estavam em curso grandes mudanças como a industrialização, acompanhada da intensa urbanização que ocorria nos países europeus e nos EUA, implicando o fenômeno da metropolização. Nesse contexto, o tema toma vulto em diferentes áreas do conhecimento como a Sociologia, a Economia e a Geografia.

No quadro geral dos estudos sobre a rede urbana, os trabalhos desenvolvidos por Walter Christaller (Die Zentralen Orte in Süddeutschland) ${ }^{3}$ são considerados clássicos da Geografia Urbana. Nesse sentido, há que ressaltar o espaço e a questão urbana já vinham sendo estudados desde muito tempo, ainda que não de forma sistemática ou institucional.

Na ciência regional, vários estudiosos forneceram subsídios teóricos para a compreensão clássica do espaço, que até então era considerado homogêneo e passível de modelização matemática, a exemplo de Alfred Weber, que tratou a teoria da localização industrial (1909), Johann $\mathrm{H}$. Von Thünen, que trabalhou as zonas concêntricas na perspectiva de um estado isolado (1826), e August Lösch (The economics of location, 1939), entre outros que se debruçaram sobre o tema ${ }^{4}$ (Vasconcelos, 1999).

Além disso, vale frisar que, conforme Vasconcelos (1999, p. 121-122), ao mencionar a contribuição de Maximilien Sorre, estudos relacionando a matemática à análise do espaço urbano já haviam sido propostos 70 anos antes dos trabalhos de Christaller.

Tais trabalhos buscavam compreender as repercussões promovidas no domínio da economia no espaço sem necessariamente considerar as contradições imanentes de uma sociedade de classes e a história, ainda que se deva sublinhar sua importância nessa discussão. Ampliavam-se as articulações entre os lugares e as interações socioespaciais, tendo em vista a difusão das redes técnicas e a expansão dos processos produtivos, com destaque para os industriais, configurando uma hierarquização dos diversos centros urbanos.

3 Com o título de Central Places in Southern Germany, a versão em inglês foi publicada em 1966.

4 Não consultamos as obras originais desses autores, mas citamo-los com base em Vasconcelos (1999). 
Os temas abordados variavam, mas, de modo geral, enfatizavam aspectos como funcionalidade econômica, área de influência das cidades, concentração e dispersão populacional, constituição de novos centros urbanos, por exemplo, propiciando o desenvolvimento de pesquisas, sobretudo na área de planejamento urbano e regional, na intenção de que elas pudessem vir a respaldar processos de reestruturação econômica, política e administrativa.

$\bigcirc$ período posterior à Segunda Guerra Mundial, por seu turno, é aquele em que mais trabalhos acadêmicos versam sobre a rede urbana. No caso brasileiro, entre as inúmeras contribuições, destacam-se as de Santos (1959), Geiger (1963) e Corrêa (1967, 1969, 1982). Convém mencionar ainda a forte influência teórica de Michel Rochefort na produção desenvolvida com esse enfoque.

No Brasil, verificou-se também um grande número de trabalhos sob a influência da Geografia Teorética Quantitativa, de perspectiva neopositivista, tanto em termos acadêmicos quanto dos institutos de pesquisa, a exemplo do IBGE.

Por outro lado, a ascensão do movimento de renovação da Geografia em meados dos anos 1970 provocou um descenso no número de trabalhos produzidos, o que só se retomou a partir dos anos 1990, com o crescimento dos debates a respeito da mundialização econômica e da importância das redes nas novas configurações produtivas e nos arranjos espaciais. Ressalte-se que a partir daí os enfoques teórico-metodológicos sofrem alterações profundas, com destaque para a produção orientada na perspectiva do materialismo histórico e dialético.

Nesse quadro, passou-se a discutir mais enfaticamente as contradições gestadas no bojo da economia capitalista e as repercussões na dinâmica da produção do espaço. Tal postura, por sua vez, teve influência direta na compreensão e na interpretação de temas até então relegados pela ciência geográfica, a exemplo da noção de desigualdade e de diferenciação socioespacial. No caso das redes urbanas, é essencial também frisar as novas possibilidades de interação a partir do aprimoramento técnico, com o desenvolvimento da internet, que tomam vulto a partir dos anos 1990. Essa mudança colocou aos investigadores do tema novos desafios, uma vez que múltiplas interações socioespaciais podem ocorrer a partir da relação entre centros urbanos com níveis hierárquicos diferentes no quadro urbano mundial.

Assim, a inter-relação passa a ter uma forma inédita até então; por exemplo, mas novas formas de comunicação implodiram os velhos esquemas hierárquicos tradicionais, que não mais explicavam a realidade em tela. Um centro de baixa dimensão demográfica pode se relacionar instantânea e simultaneamente com outros de maior porte, inclusive fora do estado ou do país. Isso não significa que a hierarquia entre eles esteja superada, pois, em termos político-administrativos e econômicos, ainda há determinados papéis de comando que exibem padrões hierárquicos.

Desse modo, ao se analisarem os arranjos espaciais que ocorrem na contemporaneidade, é preciso ter clareza de que a contiguidade territorial, ainda que se mantenha como aspecto imprescindível na compreensão dos processos constitutivos dos lugares, também resulta da articulação em rede (Sposito, 2001). Igualmente, as noções de verticalidade e de horizontalidade discutidas por Santos (1997) imprimem mais clareza à questão, sendo as cidades consideradas "pontos de intersecção". Para o autor, enquanto o suporte das horizontalidades baseia-se em contiguidade e continuidade, ou seja, em relações de vizinhança/proximidade, as verticalidades 
são balizadas por redes, articulando processos a partir de pontos seletivos do território, especialmente aqueles comandados por agentes hegemônicos, vinculando-se a ações normativas e à racionalidade do Estado.

Entretanto, a compreensão desses processos não se deve esquivar da relevância do espaço, que, mais do que nunca, é reafirmada. Porém, são inegáveis as redefinições que têm sido produzidas em função das transformações técnicas. Assim sendo, tempo e espaço devem orientar as análises como par articulado e não de modo dicotômico, sendo essenciais no entendimento da gênese dos lugares e das interações socioespaciais que neles se manifestam e redefinem a reprodução espacial. Sobre o tema, Corrêa (1999) defende que, a cada momento histórico, configurações (particulares e singulares) são redefinidas em face da divisão territorial do trabalho e da rede urbana.

Vista em suas diferentes escalas, a rede assume uma configuração específica e sua forma espacial é reveladora do momento técnico atual e, ao mesmo tempo, das contradições no modo de produção hegemônico e, portanto, das diversas divisões territoriais do trabalho que se articulam, sobrepõem-se e se sintetizam e, igualmente, negam-se, como tese, antítese e síntese da reprodução social no espaço.

Ao se observar um segmento específico de uma rede urbana é preciso, pois, atentar para suas especificidades históricas, geográficas e estruturais, bem como apreender sua complexidade (Rochefort, 1998). Nessa perspectiva, analisar uma rede exige contemplar aspectos relativos a sua gênese, evolução e dinâmica atual (Corrêa, 1989), observando-se três dimensões: a temporal (que ajuda a entender como transcorrem as alterações ao longo do tempo), a organizacional (os agentes e sua forma de estruturação) e a espacial (contemplando tanto a forma quanto as interações existentes) (Corrêa, 1997).

No curso do desenvolvimento capitalista, os processos de especialização se acentuam, resultando em cidades com diferentes portes e papéis, cuja inserção resulta em distintos níveis hierárquicos que manifestam poder em termos econômicos e políticos e, portanto, com diferentes potenciais para atrair fluxos de naturezas variadas.

As enormes diferenças regionais existentes num país da dimensão territorial do Brasil exigem, por sua vez, considerarem-se os distintos momentos de ocupação e a dinâmica das interações, resultando naquilo que Santos (1979) denominou formação socioespacial. A forte assimetria encontrada resulta de uma produção do espaço diferentemente datada, ocupada e articulada, correspondendo a áreas com mais e menos infraestruturas, capitais, pessoas e fluxos. Esses aspectos variam em muitos casos, mesmo numa mesma unidade da federação.

\section{A formação socioespacial no contexto geográfico da microrregião de Iguatemi}

$\bigcirc$ conceito de formação socioespacial foi discutido por Santos $(1979)^{5}$ com base na ideia de formação econômica e social descrita por Lênin, que, por seu turno, baseou-se em Marx. Ao enfatizar a dimensão espacial na discussão do aspecto econômico, Santos (1979) deu uma importante contribuição às análises geográficas e aqui, especialmente, ao estudo das cidades pequenas. Portanto, a categoria espaço é central na análise, tanto por sua imbricação com a

5 Santos desenvolveu esse conceito em diferentes obras, mas nos atemos ao livro Espaço e sociedade (1979). 
economia como pelo fato de ser produto de ações humanas, vindo a também influenciar seu uso posterior, relacionando-se aos diferentes modos de produção. Estes definem a forma como o espaço é usado e apropriado pelas sociedades numa relação singular, considerando ser essa a base (o espaço) para qualquer ação social, o que envolve determinado momento histórico e uma acumulação desigual de tempos e técnicas.

Na formulação desse conceito, em artigo escrito para a revista Antípode em 1977, Milton Santos desenvolve sua ideia apoiando-se em diferentes autores que estudaram a formação econômica e social, destacando que é preciso relacionar a estrutura econômica de determinada área a aspectos técnicos, fato que necessariamente deve ser articulado ao fator histórico como elemento central da constituição genética do espaço. Nessa perspectiva analítica:

$\bigcirc$ interesse dos estudos sobre as formações econômicas e sociais está na possibilidade que eles oferecem de permitir o conhecimento de uma sociedade na sua totalidade e nas suas frações, mas sempre um conhecimento específico, apreendido num dado momento de sua evolução. $\bigcirc$ estudo genético permite reconhecer, a partir de sua filiação, as similaridades entre F. E. S.; mas isso não é suficiente. É preciso definir a especificidade de cada formação, o que a distingue das outras, e, no interior da F. E. S., a apreensão do particular como uma cisão do todo, um momento do todo, assim como o todo reproduzido numa de suas frações (Santos, 1977, p. 84).

Com esse intuito, a ideia central desta discussão é abordar a forma de constituição e estruturação da rede urbana sul-mato-grossense em sua porção meridional, considerando especialmente a microrregião de Iguatemi, relacionando-a à formação socioespacial nessa área do estado. Interessa-nos discutir a singularidade existente, procurando entender a dinâmica corrente e os tipos de interações espaciais que prevalecem entre os centros que a compõem.

Assim, considera-se uma estratégia metodológica importante usar o conceito, que nos permite analisar determinada porção do espaço e do tempo, além de observar elementos técnicos presentes e o modo como eles se integram às novas e antigas demandas. "Esses objetos e essas ações são reunidos numa lógica que é, ao mesmo tempo, a lógica da história passada (sua datação, sua realidade material, sua causação original) e a lógica da atualidade (seu funcionamento e sua significação presentes)" (Santos, 1997, p. 63). Isso, por sua vez, interfere diretamente na divisão territorial do trabalho e, também, na composição regional do país, nos conteúdos sociais e espaciais.

Logo, não se pode dizer que há ilhas econômicas que pouco se articulam entre si em termos geográficos, mas sobre espaços de acumulação de capital com distintos níveis de inserção na economia capitalista. Ao discutir a regionalização do território nacional, Santos e Silveira (2001, p. 268) alertam para a existência de "quatro brasis", englobando: "uma Região Concentrada, formada pelo Sudeste e pelo Sul, o Brasil do Nordeste, o Centro-Oeste e a Amazônia". Na argumentação dos autores, fica claro que a Região Concentrada é a área mais densa do meio técnico-científico-informacional, além de apresentar maior contingente populacional e concentração econômica. $\bigcirc$ Nordeste, por outro lado, área de ocupação antiga, apesar do numeroso quadro de cidades, foi identificado como porção pouco dinâmica e com debilidade de 
articulações/interações. A Amazônia, por sua vez, é descrita como "uma região de rarefações demográficas herdadas e baixas densidades técnicas" (Santos; Silveira, 2001, p. 272). Por outro lado:

A região Centro-Oeste, constituída pelos estados de Mato Grosso, Mato Grosso do Sul, Goiás e Tocantins, é uma área de "ocupação periférica" recente. $\bigcirc$ meio técnico-científico-informacional se estabelece sobre um território praticamente "natural", ou melhor, "pré-técnico", onde a vida de relações era rala e precária. Sobre essa herança de rarefação, os novos dados constitutivos do território são os do mundo da informação, da televisão, de uma rede de cidades assentada sobre uma produção agrícola moderna e suas necessidades relacionais (Santos; Silveira, 2001, p. 271).

No quadro atual da divisão territorial do trabalho, Mato Grosso do Sul se destaca como importante fornecedor de produtos agropecuários (commodities), especialmente carne, grãos, papel e celulose e cana-de-açúcar, além de minérios e minerais não metálicos (a exemplo do calcário), entre outros, fortemente franqueados por capitais corporativos hegemônicos pela Região Concentrada face às demandas da globalização.

Verificadas essas questões da dinâmica regional do Centro-Oeste, é preciso considerar ainda alguns fatores que são importantes para melhor compreender os processos hoje em curso em Mato Grosso do Sul. Assim, ainda que seja fundamental discutir a dimensão temporal para interpretar a formação socioespacial, limitar-nos-emos a ressaltar sucintamente aspectos mais contemporâneos para situar o tema.

desenvolvimento de políticas regionais estimuladas pela União, no âmbito do então estado de Mato Grosso, intensificou-se especialmente a partir do governo Vargas (1930-1945). Segundo Duarte (1989, p. 15), antes, a região Centro-Oeste estava "à margem do processo de acumulação capitalista" no que tange ao polo mais dinâmico da economia, situado no Sudeste. A debilidade nas comunicações e no sistema de circulação, bem como sua densidade populacional rarefeita e mercado pouco expressivo, representavam entraves a uma maior integração econômica, algo que foi, paulatinamente, sendo modificado a partir de diferentes políticas públicas de intervenção do Estado.

Quanto à porção sul do estado, o estímulo à colonização oficial ocorreu em 1943, com a instalação da Cand no contexto da política "Marcha para o Oeste", uma vez que houve distintos movimentos de ocupação territorial oriundos especialmente de São Paulo, Minas Gerais e Paraná. Nessa perspectiva, é preciso ter em mente que a porção sul do estado resulta de um desmembramento de Corumbá (Gressler; Swensson, 1988), que originou os demais municípios como os conhecemos hoje.

A partir do estímulo à ocupação não indígena promovida pelo governo, também houve iniciativas de empresas privadas de colonização que redundaram na criação de uma série de núcleos urbanos nessa área, depois transformados em sedes de município, a exemplo de Fátima do Sul, Deodápolis, Glória de Dourados, Jateí, Vicentina, Angélica, Ivinhema e Itaporã, entre outros (Oliveira, 1999). A esse respeito, Calixto (2004) destacou as transações financeiras com terras urbanas e rurais como originárias dessas iniciativas, instaurando-se uma progressiva valorização imobiliária. 
Inicialmente, as repercussões socioespaciais ficaram restritas à dinâmica regional, mas serviram como alicerce para as profundas alterações desencadeadas a partir dos anos 1960 , com a criação de Brasília, a implantação de infraestrutura viária e de telecomunicações e os programas de desenvolvimento regional, com diferentes objetivos. Em termos gerais, esse contexto foi acompanhado pelo processo de industrialização e modernização do território (cidade e campo), com destaque para São Paulo (Cano, 1975; Becker; Egler, 1993).

Ainda nesse cenário, o planejamento regional torna-se mais evidente no país por meio de políticas públicas que visavam integrar e ampliar a urbanização, o crescimento econômico e a interiorização da ocupação, com vistas a proteger o território em termos geopolíticos e de soberania nacional. Essas ações vinham sendo empreendidas desde Vargas, mas foram reforçadas no governo do presidente Juscelino Kubitschek e, posteriormente, no quadro do regime militar (1964-1985), difundindo uma racionalização do território cujo objetivo principal era a maior integração econômica interna e com o mercado exterior (Becker; Egler, 1993).

Já a criação da Superintendência para o Desenvolvimento do Centro-Oeste (Sudeco), em 1967, objetivou, com o planejamento regional, imprimir maior racionalidade à economia (Duarte, 1989), desenvolvendo-se novas estratégias espaciais e de uso do território.

No bojo dessas grandes mudanças, merecem referência os incentivos e os financiamentos a grandes projetos agropecuários, que levaram à constituição e ao fortalecimento de diversos órgãos como a Empresa Brasileira de Pesquisa Agropecuária (Embrapa) e o Instituto Nacional de Colonização e Reforma Agrária (Incra), entre outros, que estavam articulados ao Plano de Integração Nacional (PIN) e ao Programa de Desenvolvimento do Centro-Oeste (Prodoeste), contexto em que ocorre o programa de corredores de exportação na porção sul do então Mato Grosso, facilitando a comercialização de commodities como a soja (Abreu, 2001).

Outros programas, realizados durante o II PND (1975-1979), foram o Programa de Desenvolvimento dos Cerrados (Polocentro), que incentivou a modernização da agricultura na região, o Programa de Desenvolvimento da Região da Grande Dourados (Prodegran), o Programa de Desenvolvimento do Pantanal (Prodepan) e, com a divisão do estado do Mato Grosso, o Programa de Desenvolvimento do Estado do Mato Grosso do Sul (Prosul) (Abreu, 2001). Tais políticas foram seletivas, tendo sido seus recursos concentrados nas cidades de maior porte e de dinamismo econômico, especialmente Dourados e Campo Grande.

O processo de modernização da agricultura efetiva-se na porção sul do estado especialmente a partir do fim da década de 1970. Analisando dados referentes à evolução populacional entre 1970 e 2010, verificamos que muitos municípios surgiram depois dos anos 1970, justificando-se parte da perda populacional de alguns deles como decorrente de sucessivos desmembramentos municipais. Entretanto, o processo de tecnificação do campo também deve ser considerado um vetor, bem como a expansão da fronteira agrícola para a região amazônica (especialmente norte de Mato Grosso, Amazonas, Rondônia, Acre e Pará), que incidiu no decréscimo da população do campo. 
Desse modo, a expansão do capitalismo, incorporando novas áreas do território, impactou no processo de urbanização regional, com parcela da população migrando para cidades maiores, como Campo Grande e Dourados. Ressaltamos que a atratividade exercida pelo espaço urbano é um componente que também precisa ser destacado, levando-se em conta a possibilidade que oferece de maiores salários, melhores condições de vida e acesso a serviços educacionais, de saúde e ao consumo em geral.

A população total da microrregião de Iguatemi é de 226.332 habitantes, segundo dados do Censo Demográfico de 2010 (IBGE, 2010), dos quais 38,09\% residem em áreas rurais e 61,91\% em áreas urbanas; isto é, ainda que a população urbana seja mais expressiva, a rural apresenta-se de modo destacado. Os municípios de Itaquiraí, Japorã, Jateí, Paranhos e Tacuru são os que apresentam maior percentual de população vivendo em espaço rural, com destaque para Japorã, com 81,89\% (IBGE, 2010).

É importante analisar também que a microrregião de lguatemi encontra-se num contexto fronteiriço, sendo que alguns de seus municípios fazem divisa com o Paraguai, em particular Sete Quedas, Mundo Novo e Japorã.

Há, desse modo, grandes interações socioespaciais, inclusive na perspectiva cultural. Além disso, a fronteira apresenta enorme complexidade para sua compreensão, havendo trocas tanto materiais quanto imateriais na produção da sociabilidade local e regional que extravasa os limites formais dos Estados Nacionais. Trata-se, portanto, de um território extremamente poroso e aberto a forte relacionamento, tanto no que tange às mercadorias lícitas quanto aos produtos de origem ilícita. Conseqüentemente, pode-se escrever que a fronteira é o espaço da expectativa de reprodução ampliada para praticamente todos os atores em jogo, mas onde há incerteza quanto a essa reprodução, na medida em que as ações sociais respondem a orientações políticas e valorativas e não só aos constrangimentos econômicos, condição que the atribui valor dinâmico e estratégico [...] (Becker, 1988, p. 67).

Analisando a incorporação do modo de vida urbano pela fronteira mato-grossense no início do século XX, Oliveira Neto (2006, p. 208) enfatizou que a ocupação da porção sul, especialmente a partir do fim da Guerra do Paraguai (1864-1870), acentuou-se, visto que: "para a região, a necessidade da constituição de novas cidades já era imperiosa [...]. Aquele conflito determinou a urgência do Brasil em ocupar sua área de fronteira".

Assim, o fluxo de pessoas entre Brasil e Paraguai é outra realidade que decorre dessa proximidade, de modo que a designação "brasiguaios" é muito comum na microrregião.

Todavia, apesar do incentivo à ocupação, incluindo a formação de vilarejos que depois vieram a se tornar centros urbanos, a importância do rural ainda se sobressai no século XXI, seja na paisagem, no lugar de residência ou como modo de vida nessa microrregião. Acerca disso, enfatiza-se a presença de muitos assentamentos da reforma agrária na área em foco, tendo em vista a atuação de movimentos sociais de luta pela terra a partir dos anos 1980. Esses 
movimentos resultaram na implantação de assentamentos nesses municípios, ressaltando-se Itaquiraí, com 2.705 famílias camponesas distribuídas em 12 projetos (Itaquiraí, [s.d.]). Permanências e transformações são, nessa perspectiva, inerentes à formação socioespacial e ao conjunto de especificidades que aí se materializam, sintetizam-se e se negam contraditoriamente. Nesse sentido:

$\bigcirc$ modo de produção expressa-se pela luta e por uma interação entre o novo, que domina, e o velho. $\bigcirc$ novo procura impor-se por toda parte, porém, sem poder realizar isso completamente. $\bigcirc$ velho é o modo de produção anterior, mais ou menos penetrado pelas formas sociais e pelas técnicas que correspondem ao modo de produção novo, mas sempre comandado pelo modo de produção novo. Daí chamar-se a esse modo de produção "atual", em plena existência, um modo de produção puro: ele não se realiza completamente em parte alguma [...] (Santos, 1977, p. 77).

A despeito da historicidade relativa à ocupação não indígena, uma dessas permanências significativas é o fato de que Mato Grosso do Sul abriga a segunda maior população indígena do país, e é importante considerar essa presença na microrregião. Tacuru, por exemplo, tem duas aldeias (Jaguapiré e Sassoró), além de três assentamentos, e a influência indígena se faz sentir tanto no fato de o guarani ser considerado língua oficial no município quanto no de algumas das festas locais remeterem a essa especificidade cultural (Festa da Mandioca e Feira do Peixe), além de a cidade contar com uma Secretaria de Assuntos Indígenas.

A porção sul do estado, onde se insere a microrregião de Iguatemi, é a que tem maior fragmentação territorial, posto que congrega o maior número de municípios, esses que, em geral, têm menor extensão territorial. Isso se reflete também no conjunto de centros urbanos (sedes municipais) que se enquadram como cidades pequenas, o que necessariamente envolve a discussão sobre a formação socioespacial.

A esse respeito, Corrêa (2000) identificou relações entre a questão fundiária e a própria tipologia de cidades na rede urbana, arrolando sete pontos para a análise do tema - um dos quais relaciona a pequena propriedade à maior presença de cidades pequenas. Já em outro sentido, a maior concentração fundiária pode resultar na produção de menos municípios e em cidades maiores.

Santos e Silveira (2001), por sua vez, afirmaram que o fato de a ocupação da região Centro-Oeste ter sido mais recente, logo franqueada por vetores de modernização que permitiram uma produção agropecuária tecnificada e cuja articulação ao mercado foi desenvolvida por rodovias e infovias, possibilitou a criação e a manutenção de centros urbanos mais distantes entre si.

A esse respeito, cabe considerar ainda que no período contemporâneo as articulações que extravasam os limites do território nacional se fazem presentes na área em estudo, principalmente a partir da atuação de capitais com nexos globais, a exemplo das empresas sucroalcooleiras presentes nesse recorte territorial (Quadro 1). 


\section{Quadro 1 - Empresas sucroalcooleiras na microrregião de Iguatemi-MS}

\begin{tabular}{|l|l|c|}
\hline municípios & empresas sucroalcooleiras & ano de início \\
\hline Angélica & Adecoagro (Grupo Biosev) & 2007 \\
\hline Iguatemi & Usina Dcoil & 2002 \\
\hline Ivinhema & Adecoagro (Grupo Biosev) & 2011 \\
\hline Naviraí & Usinavi - Infinity Bio-Energy & 1984 \\
\hline
\end{tabular}

fonte: Nova Cana e sítios institucionais das empresas (2017).

A Adecoagro (Grupo Biosev) (Adecoagro, [s.d.]) iniciou sua operação na Argentina, tendo presença no Brasil e no Uruguai e desenvolvendo atividades ligadas à produção de diferentes commodities agrícolas, mantendo unidades nos municípios de Angélica e Ivinhema e estendendo sua influência territorial a cidades como Novo Horizonte do Sul, Deodápolis, Glória de Dourados e Jateí. A companhia negocia igualmente ações na bolsa de Nova York sob a denominação "agro".

Outro exemplo é a Usinavi, que atua no município de Naviraí desde 1984, tendo sido adquirida pelo grupo Infinity Bio-Energy Brasil Participações S/A em 2006, segundo o Relatório de Impactos Ambientais disponibilizado em sítio governamental de Mato Grosso do Sul (Toposat Ambiental, [2007], p. 11). Já no portal da Nova Cana ([s.d.]), se verifica que a companhia passou a compor a "Tinto Holding, do grupo de energia e infraestrutura Bertin, que adquiriu $71 \%$ dos ativos da companhia, passando a controlá-la". $\bigcirc$ mesmo sítio informa ainda que a empresa passa por várias dificuldades, entre as quais, "atraso de salários de trabalhadores e demissões em massa no caso da unidade sul-mato-grossense de Naviraí". Portanto, em que pese o forte conteúdo espacial herdado, verificamos que múltiplas verticalidades vêm atingindo incisivamente essa microrregião. Nessa perspectiva:

Apesar da força da ordem global, a região pode ser compreendida como um tecido contínuo e heterogêneo de modernidades e formas herdadas, materiais e imateriais, que constituem horizontalidades [...]. Todavia, hoje, mais do que nunca, é resultado de interdependências e de uma oposição dialética entre uma ordem global e uma ordem local, com a mediação tantas vezes sem defesa da formação socioespacial. Nesse retrato, a ordem global surge como autorreferenciada, já que sua finalidade é o próprio mercado global, enquanto a ordem local pode abrigar o sentido da vida social (Silveira, 2010, p. 77).

Essa realidade impõe um novo desafio aos estudiosos das Ciências Humanas, uma vez que a ideia de região, e mesmo de formação socioespacial, passa por um processo contínuo de reflexão e construção conceitual.

Com esse intuito, o IBGE divulgou recentemente uma nova regionalização no país, estabelecendo um recorte tendo como base o estabelecimento de regiões geográficas imediatas e regiões geográficas intermediárias, identificando as principais cidades que polarizam 
a rede urbana e os municípios que a ela estão vinculados. No caso de Mato Grosso do Sul, estabeleceram-se três regiões geográficas intermediárias, quais sejam: a de Campo Grande, a de Corumbá e a de Dourados. Importa-nos aqui destacar que Dourados apresenta como regiões imediatas, por sua vez, além da cidade que leva seu nome, Ponta Porã, Amambaí, Nova Andradina e Naviraí-Mundo Novo, esta última abarcando, por seu turno, grande parte dos municípios que até então pertenciam à microrregião de Iguatemi.

No caso de Naviraí-Mundo Novo, os municípios que compõem essa região imediata são Naviraí, Iguatemi, Itaquiraí, Japorã, Eldorado e Mundo Novo. As demais localidades que compunham a chamada microrregião de Iguatemi foram redistribuídas em outras regiões imediatas.

Nesse sentido, cumpre frisar que a regionalização proferida pelo IBGE aproxima-se, em termos mais realistas, da formação socioespacial que produziu a configuração urbano-regional. Contudo, é preciso considerar que toda regionalização tem contradições. No caso da região em tela, observa-se uma aglutinação de municípios que não faziam parte de uma mesma rede urbana articulada, como é o caso da região imediata de Nova Andradina, que abriga Ivinhema e Angélica, cidades que desde os primórdios da colonização pela Cand têm mais conexão e ligação com Dourados, em termos de fluxos de capitais e de pessoas. Assim, é oportuno retomar Santos (1977, p. 87-88):

As relações entre espaço e formação social são de outra ordem, pois elas se fazem num espaço particular e não num espaço geral, tal qual para os modos de produção. Os modos de produção escrevem a História no tempo, as formações sociais escrevem-na no espaço.

Frente ao exposto, a interpretação desse recorte do espaço geográfico e de sua dinâmica em Mato Grosso do Sul pretendeu, dentro da pluralidade existente, destacar as especificidades dessa porção do território, abordando-a a partir do conceito de formação socioespacial.

Com isso, é importante frisar que, especificamente na microrregião, há 14 centros locais, com base nos dados da Regic (IBGE, 2008) ainda que haja algumas cidades, a exemplo de Ivinhema e Naviraí, que têm mais importância econômica na rede urbana, dadas as companhias instaladas em seus territórios que estão articuladas ao capital global, sobretudo por conta da produção sucroalcooleira.

Nesses termos, constata-se que, embora analisada a porção meridional de Mato Grosso do Sul, o tema da rede urbana extrapola o significado regional para se relacionar a cidades mais distantes. Desse modo, as interações são amplas e dão novo significado à região. Entretanto, permanecem as heranças socioespaciais da gênese das localidades e outras ganham novos conteúdos, rearticulando-se, contraditoriamente, a partir desses nexos econômicos.

\section{Considerações finais}

Pela leitura da rede urbana e da formação socioespacial no contexto da microrregião de Iguatemi, podemos avaliar dois vetores muito presentes na dinâmica da produção do espaço: (I) um ligado à dimensão interna das relações sociais, econômicas, políticas e culturais já existentes 
e que são matrizes da tessitura social posta, resultante de processos histórico-espaciais herdados do universo da fronteira e da grande propriedade rural (Mate Laranjeira), que gerou essa formação socioespacial que depois foi redefinida pelo processo oficial de colonização a partir de ações do Estado que reconfiguraram o território, e (II) um ligado às novas e modernas atividades relativas às demandas da globalização e da mundialização do capital, que interferem diretamente nos arranjos produtivos, impondo uma nova configuração socioespacial pela inserção de commodities, mecanização do campo, tecnificação e bioengenharia produtiva, com destaque para soja, milho, cana-de-açúcar e ainda para a pecuária de corte, galináceos (corte) e suínos.

Daí decorre uma refuncionalização, sobretudo nos núcleos urbanos vinculados a uma especialização produtiva, como acontece com o setor sucroalcooleiro. Assim, pode-se falar num grande complexo agroindustrial que articula inclusive as lógicas urbanas da cidade; nesse caso, tende a aumentar a centralidade de cidades pequenas como Ivinhema e Naviraí.

Ao mesmo tempo, é preciso lembrar a possibilidade de a permanência se manifestar na dinâmica do conteúdo urbano. Essa característica pode ser encontrada em centros pequenos, com caráter funcional mais local, menos centrais no quadro urbano geral e com uma produção que atende ao município e a sua região imediata, ou seja, de alcance espacial mínimo.

Isso não significa que não existam agentes sociais que possam transformar a dinâmica local, atuando de forma articulada e de modo a ampliar seus ganhos e seu raio de ação nesse território. As fecularias são um exemplo patente dessa lógica, mobilizando capitais, pessoas e organizações que envolvem assentamentos e usando como base um produto tradicional, a mandioca, e ainda se relacionando com populações indígenas presentes na microrregião, a exemplo de Tacuru.

Esse quadro permite concluir que a microrregião de Iguatemi tem particularidades (algumas cidades mais ligadas à atuação de capitais hegemônicos, enquanto outras têm dinâmica de capital mais local) no arranjo da rede urbana e da formação socioespacial e que é preciso pensar a cidade em articulação com o campo.

Evidentemente, essa postura nos impõe o desafio de refletir sobre o modo como a modernização e os aspectos mais tradicionais da dimensão social e econômica se imbricam na produção do espaço e, por conseguinte, nas cidades pequenas que compõem essa microrregião, patenteando-se uma forte complementaridade nas relações cidade-campo.

\section{Referências}

ABREU, S. Planejamento governamental: a Sudeco no espaço mato-grossense, contexto, propósitos e contradições. Tese (Doutorado em Geografia Humana) - Faculdade de Filosofia, Letras e Ciências Humanas, Universidade de São Paulo, São Paulo, 2001.

ADECOAGRO. Informações sobre a empresa. Disponível em: http://www.adecoagro.com/ home.aspx. Acesso em: 31 maio 2017.

BECKER, B. K. Significância contemporânea da fronteira: uma interpretação geopolítica a partir da Amazônia Brasileira. In: AUBERTIN, C. (Org.). Fronteiras. Brasilia: Ed. UNB, 1988. p. 60-89. 
BECKER, B. K.; EGLER, C. A. Brasil: uma nova potência regional na economia-mundo. Rio de Janeiro: Bertrand Brasil, 1993.

BERNARDELLI, M. L. F. H. Pequenas cidades na região de Catanduva-SP: papéis urbanos, reprodução social e produção de moradias. Tese (Doutorado em Geografia) - Faculdade de Ciências e Tecnologia, Universidade Estadual Paulista, Presidente Prudente, 2004.

CALIXTO, M. J. M. S. Produção, apropriação e consumo do espaço urbano: uma leitura geográfica da cidade de Dourados, MS. Campo Grande: Ed. UFMS, 2004.

CAMAGNI, R. Organisations économiques et réseaux de villes. In: SALLEZ, A. (Dir.). Les villes, lieux d'Europe. Paris: Datar/L'Aube, 1993, p. 107-128.

CANO, W. Raízes da concentração industrial em São Paulo. Tese (Doutorado em Ciências Econômicas) - Instituto de Filosofia e Ciências Humanas, Universidade Estadual de Campinas, Campinas, 1975.

CARLOS, A. F. A. Seria o Brasil menos urbano do que se calcula? In: CARLOS, A. F. A. O espaço urbano: novos escritos sobre a cidade. São Paulo: FFLCH, 2007. p. 103-108. Disponível em: http://gesp.fflch.usp.br/sites/gesp.fflch.usp.br/files/Espaco_urbano.pdf. Acesso em: 22 mar. 2017.

CHRISTALLER, W. Central places in Southern Germany. Englewood Cliffs: Prentice-Hall, 1966.

CORREAA, R. L. Rede urbana e formação espacial: uma reflexão considerando o Brasil. Território, Rio de Janeiro: Laget/UFRJ, v. 8, n. 8, p. 121-129, 2000.

CORRÊA, R. L. Globalização e reestruturação da rede urbana: uma nota sobre as pequenas cidades. Território, Rio de Janeiro: Laget/UFRJ, v. 6, n. 6, p. 43-53, jan./jun. 1999.

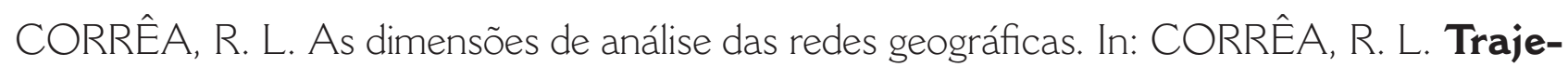
tórias geográficas. Rio de Janeiro: Bertrand Brasil, 1997. p. 107-118.

CORRÊAA, R. L. A rede urbana. São Paulo: Ática, 1989.

CORREAA, R. L. Repensando a teoria das localidades centrais. In: SANTOS, M. (Coord.).

Novos rumos da geografia brasileira. São Paulo: Hucitec, 1982. p. 50-65.

CORREA, R. L. Os estudos de redes urbanas no Brasil. Revista Brasileira de Geografia, Rio de Janeiro, v. 31, n. 1, p. 43-56, 1969.

CORREAA, R. L. Estudo das relações entre cidade e região. Revista Brasileira de Geografia, Rio de Janeiro, n. 4, p. 93-116, 1967.

DCOIL. Informações sobre a empresa. Disponível em: http://www.dcoil.com.br/. Acesso em: 31 maio 2017.

DUARTE, A. C. O Centro-Oeste na organização regional do Brasil. In: IBGE. Região Centro-Oeste. Rio de Janeiro: IBGE, 1989. p. 15-20. 
ENDLICH, A. M. Pensando os papéis e significados das pequenas cidades no noroeste do Paraná. Tese (Doutorado em Geografia) - Faculdade de Ciências e Tecnologia, Universidade Estadual Paulista, Presidente Prudente, 2006.

FRESCA, T. M. A dinâmica funcional da rede urbana do oeste paulista. Estudo de casos: Osvaldo Cruz e Inúbia Paulista. Dissertação (Mestrado em Geografia) - Centro de Ciências Humanas, Universidade Federal de Santa Catarina, Florianópolis, 1990.

GEIGER, P. P. Evolução da rede urbana brasileira. Rio de Janeiro: CBPE, 1963.

GRESSLER, L. A.; SWENSSON, L. J. Aspectos históricos do povoamento e da colonização do Estado de Mato Grosso do Sul: destaque especial ao município de Dourados. Dourados: [S.e.], 1988.

HAESBAERT, R. Des-territorialização e identidade: a rede "gaúcha" no Nordeste. Niterói: Ed. UFF, 1997.

IBGE. INSTITUTO BRASILEIRO DE GEOGRAFIA E ESTATÍSTICA. Divisão regional do Brasil em regiões geográficas imediatas e regiões geográficas intermediárias. 2017a. Disponível em: https://biblioteca.ibge.gov.br/visualizacao/livros/liv100600.pdf. Acesso em: 16 ago. 2018.

IBGE. INSTITUTO BRASILEIRO DE GEOGRAFIA E ESTATÍSTICA. Cidades. $2017 \mathrm{~b}$. Disponível em: http://ibge.gov.br/cidadesat/xtras/perfil.php. Acesso em: 24 abr. 2017.

IBGE. INSTITUTO BRASILEIRO DE GEOGRAFIA E ESTATÍSTICA. Censo Demográfico 2010. Disponível em: http://www.ibge.gov.br/home/estatistica/populacao/ censo2010/default.shtm. Acesso em: 24 abr. 2017.

IBGE. INSTITUTO BRASILEIRO DE GEOGRAFIA E ESTATÍSTICA. 2008. Regiões de influência das cidades. Rio de Janeiro: IBGE, 2008.

ITAQUIRAÍ. Prefeitura Municipal. Disponível em: http://www.itaquirai.ms.gov.br/aspectos-geograficos/. Acesso em: 15 nov. 2017.

JURADO DA SILVA, P. F; SPOSITO, E. S. Discussão geográfica sobre cidades pequenas. Geografia, Rio Claro: Ageteo, v. 34, n. 2, p. 203-217, maio/ago. 2009.

NOVA CANA. Informações sobre o setor sucroalcooleiro. Disponível em: https:// www.novacana.com/usinas-brasil/grupo/infinity-bio-energy/. Acesso em: 31 maio 2017.

OLIVEIRA NETO, A. F. A incorporação do modo de vida urbano na região de fronteira do sul do território mato-grossense no início do séc. XX. In: SPOSITO, M. E. B.; WHITACKER, A. M. (Org.). Cidade e campo: relações e contradições entre urbano e rural. São Paulo: Expressão Popular, 2006. p. 205-215.

OLIVEIRA, B. C. Desdobramentos da Marcha para Oeste na fronteira Brasil-Paraguai: colonizar era preciso. In: OLIVEIRA, B. C. (Org.). Histórias que (re)contam história: análise do povoamento, colonização e reforma agrária do sul de Mato Grosso do Sul. Dourados: Ed. UFGD, 2013. p. 13-28. 
OLIVEIRA, B. C. A política de colonização do estado novo em Mato Grosso(1937-1945). Dissertação (Mestrado em História) - Faculdade de Ciências e Letras, Universidade Estadual Paulista, Assis, 1999.

ROCHEFORT, M. Redes e sistemas: ensinando sobre o urbano e a região. São Paulo: Hucitec, 1998.

SANTOS, M. A natureza do espaço: técnica e tempo, razão e emoção. São Paulo: Hucitec, 1997.

SANTOS, M. Espaço e sociedade. Petrópolis, RJ: Vozes, 1979.

SANTOS, M. Sociedade e espaço: a formação social como teoria e como método. Boletim Paulista de Geografia, São Paulo, n. 54, p. 81-97, jun. 1977.

SANTOS, M. A cidade como centro de região: definições e métodos de avaliação da centralidade. Salvador: Progresso, 1959.

SANTOS, M.; SILVEIRA, M. L. O Brasil: território e sociedade no início do século XXI. Rio de Janeiro: Record, 2001.

SILVEIRA, M. L. Região e globalização: pensando um esquema de análise. Redes, Santa Cruz do Sul, v. 15, n. 1, p. 74-88, jan./abr. 2010.

SOARES, B. R. Planos diretores em municípios de pequeno porte: reflexões a partir de experiências multidisciplinares. Formação, Presidente Prudente, v. 2, n. 15, p. 13-24, 2008.

SOBARZO, O. O urbano e o rural em Henri Lefebvre. In: SPOSITO, M. E. B.; WHITACKER, A. M. (Org.). Cidade e campo: relações e contradições entre urbano e rural. São Paulo: Expressão Popular, 2006. p. 53-64.

SPOSITO, M. E. B. As cidades médias e os contextos econômicos contemporâneos. In: SPOSITO, M. E. B. (Org.). Urbanização e cidades: perspectivas geográficas. Presidente Prudente: FCT/Unesp, 2001. p. 609-643.

TOPOSAT AMBIENTAL. Relatório de Impacto Ambiental (Rima): Usina Naviraí S/A Açúcar e Álcool. Naviraí, [2007]. Disponível em: http://www.servicos.ms.gov.br/imasuldownloads/rimas/USINANAVIRAI.pdf. Acesso em: 31 maio 2017.

VASCONCELOS, P. A. Dois séculos de pensamento sobre a cidade. Ilhéus: Editus, 1999. 